\title{
Reducing Covid-19 and Future Pandemic Mortality by Eliminating Obesity Comorbidity
}

\author{
Robert L Cucin* \\ Division of Plastic Surgery, Presbyterian New York Hospital, USA
}

*Corresponding author: Robert L Cucin MD JD MBA FACS, Division of Plastic Surgery, Presbyterian New York Hospital, Clinical Instructor in Plastic Surgery at the Weill Cornell Medical School in NYC, New York, USA, Tel: 212-586-9500; Email: robert@cucin.com
Letter to Editor

Volume 4 Issue 1

Received Date: April 16, 2020

Published Date: May 11, 2020

DOI: $10.23880 /$ ijsst- 16000145

\section{Letter to the Editor}

It seems likely that the increased prevalence of obesity in older adults in Italy compared to China may account for the differences in mortality between the two countries. Furthermore, the rising prevalence of obesity in the US and prior experience of the impact of obesity on mortality from H1 N1 Influenza should increase the sensitivity of clinicians caring for patients with obesity and COVID-19 to the need for aggressive treatment of such patients [1].

Researchers in Lille, France analyzed the relationship between clinical characteristics, including body mass index (BMI), and the requirement for invasive mechanical ventilation in 124 consecutive patients admitted in intensive care for SARS-CoV-2. The study showed a high frequency of obesity among patients admitted in intensive care for SARS$\mathrm{CoV}-2$ and that disease severity increased with BMI. The researchers concluded that Obesity is a risk factor for SARS$\mathrm{CoV}-2$ severity requiring increased attention to preventive measures in susceptible individuals [2].

Luzzi and Radielli propose that quarantine of obese subjects be extended longer than nonobese patients and note that evidence from previous influenza pandemics suggests improving immune function by losing weight with a mild caloric restriction; including AMPK activators and PPAR gamma activators in the drug treatment for obesity associated with diabetes; and mild-to-moderate physical exercise [3].

Singh and Misra note that since hydrocholoroquine has been improved for diabetes mellitus in India and early studies have shown it to improve parameters in patients with COVID-19 in some small studies, it should be further researched in diabetes and COVID-19, a subgroup where significant mortality has been shown [4].
Muniyappa and Gubbi reviewed ways in which diabetes mellitus modulates the host viral interaction and host immune responses to increase morbidity. Gupta, Gosh, et al. [5] advocate methods to prevent disease in patients with diabetes: maintain a good glycemic control with more frequent monitoring of blood glucose levels, stabilize coexisting cardiac or/renal disease, assure adequate nutrition and protein intake, address any deficiencies of minerals and vitamins need to be taken care of. Exercise has been shown to improve immunity and it is important to provide influenza and pneumonia vaccinations [6]. On 4/5/20, The New York Times reported Black Americans are being disproportionately affected by COVID-19. The increased incidence of obesity among the Black population who are concentrated in our inner cities is most likely responsible.

As it is the visceral or "belly fat" within the abdomen which secretes resistin, a cellular hormone which antagonizes the body's own insulin to cause type 2 diabetes, reducing the size of that noxious cytokine factory which functions as a lifeshortening gland with Endoscopic Visceral Lipectomy (EVL) is a direct approach to the problem. Using an endoscopic generation of a technology originally developed to facilitate safer and less onerous liposuction (Twin Cannula Assisted Liposuction or "TCAL"), a tube-within- a-tube tissue removal device that does not require the surgeon to actively stroke or reciprocate an aspirating cannula, [7] the endoscopic visceral lipectomy device under development $(E V L \circledast$, BioSculpture Technology, Inc.) will permit laparoscopic assessment, of which intraabdominal fat is the most noxious and to safely and efficiently remove it permanently [8].

EVL does not require cutting into the bowel or stomach, rearranging the body's alimentary plumbing, leaving behind 


\section{International Journal of Surgery \& Surgical Techniques}

a foreign body, or have any danger of creating malabsorption syndromes and nutritional cripples. Clinical testing and regulatory approvals are yet to be obtained. But, if EVL in humans attains postsurgical weight loss and metabolic improvement similar to visceral lipectomy in animals [9-12] it holds potential of not only becoming a first-line procedure in the treatment of established metabolic syndrome and type 2 diabetes but also of significantly widening patient selection to affect the course of the disease. If we can prevent an obese teen from becoming the obese mother of an obese infant [13] prone to type 2 diabetes at birth, we can reduce the $9.6 \%$ annual growth rate of obesity [14].

The author recommends that a generational effort be made to reduce the vulnerability of large sectors of the population to COVID-19 and future pandemics by recognizing the need to fortify the host immune system and normalize metabolism before attack. Obesity, metabolic syndrome and type 2 diabetes need not just to be managed and controlled, but efforts should be made to prevent, eliminate and cure them. Governments need make existing modalities and treatments (diet, exercise, medical, surgical, behavioral) available to all those affected, especially those in inner cities, and to fund development of promising new methods and approaches. Otherwise these soft target hosts will be breeding pools for contagious diseases and comprise the majority of this and our next pandemic's patient admissions and mortalities. If we do not improve the health of the herd by our choices and actions, nature will cull it and all of us will share the grief and costs.

\section{Conflict of Interest}

Dr. Cucin serves as C.E.O. of BioSculpture Technology, Inc., a U.S. medical device manufacturer that is developing the EVL $\AA$ device.

\section{References}

1. William Dietz, Carlos Santos-Burgoa (2020) Obesity and its Implications for COVID-19 Mortality.

2. Simonnet A, Chetboun M, Poissy J, Raverdy V, Noulette J, et al. (2020) High prevalence of obesity in severe acute respiratory syndrome coronavirus-2 (SARS-CoV-2) requiring invasive mechanical ventilation.

3. Luzi L, Radaelli MG (2020) Influenza and obesity: its odd relationship and the lessons for COVID-19 pandemic. Acta Diabetol.
4. Singh AK, Singh A, Shaikh A, Singh R, Misra A (2020) Chloroquine and hydroxychloroquine in the treatment of COVID-19 with or without diabetes: A systematic search and a narrative review with a special reference to India and other developing countries. Diabetes Metab Syndr 14(3): 241-246.

5. Gupta R, Ghosh A, Singh AK, Misra A (2020) Clinical considerations for patients with diabetes in times of COVID-19 epidemic. Diabetes Metab Syndr 14(3): 211212.

6. Muniyappa R, Gubbi S (2020) COVID-19 Pandemic, Corona Viruses, and Diabetes Mellitus. Am J Physiol Endocrinol Metab 318(5): E736-E741.

7. Becker DG, Cucin RL San Diego (2000) Chapter: Powered liposuction. In: Powered Instrumentation in Surgery. California: Singular Publishing Group.

8. Cucin RL (2017) Letters to the Editor: Mckinsey's obesity Prevalence Projections may be Low! A New Approach, Endoscopic Visceral Lipectomy ("EVL") May Offer a Solution. BAOJ Diabet 3: 027.

9. Muzumdar R, Allison DB, Huffman DM, Ma X, Atzmon G, et al. (2020) Visceral adipose tissue modulates mammalian longevity. Aging Cell 7: 438-440.

10. Huffman DM, Barzilai N (2010) Contribution of adipose tissue to health span and longevity. Interdiscip Top Gerontol 37: 1-9.

11. Pitombo C, Araujo EP, De Souza CT, Pareja JC, Geloneze B, et al. (2006) Amelioration of diet-induced diabetes mellitus by removal of visceral fat. J Endocrinol 191(3): 699-706.

12. Gabriely I, Barzilai N (2003) Surgical removal of visceral adipose tissue: Effects on insulin action Curr Diab Rep 3(3): 201-206.

13. Jovanovic-Peterson L, Crues J, Durak E, Peterson CM (1993) Magnetic resonance imaging in pregnancies complicated by gestational diabetes predicts infant birthweight ratio and neonatal morbidity. Am J Perinatol 10(6): 432- 437.

14. Cucin RL (2018) Uncoiling the Tightening Obesity Spiral. Clin Res Diab Endocrinol 1(2): 1-5. 